\title{
BMJ Open What are junior doctors for? The work of Foundation doctors in the UK: a mixed methods study
}

\author{
Gillian Vance, ${ }^{1}$ Sharmila Jandial, ${ }^{1}$ Jon Scott, ${ }^{1,2}$ Bryan Burford ${ }^{1}$
}

To cite: Vance G, Jandial S, Scott J, et al. What are junior doctors for? The work of Foundation doctors in the UK: a mixed methods study. BMJ Open 2019;9:e027522. doi:10.1136/ bmjopen-2018-027522

- Prepublication history and additional material for this paper are available online. To view these files, please visit the journal online (http://dx.doi. org/10.1136/bmjopen-2018027522).

Received 31 October 2018 Revised 4 February 2019 Accepted 15 February 2019

Check for updates

(c) Author(s) (or their employer(s)) 2019. Re-use permitted under CC BY-NC. No commercial re-use. See rights and permissions. Published by BMJ.

${ }^{1}$ School of Medical Education, Newcastle University, Newcastle Upon Tyne, UK

${ }^{2}$ Northern Foundation School, Health Education England working across North East and North Cumbria, Newcastle Upon Tyne, UK

Correspondence to

Dr Gillian Vance;

gillian.vance@ncl.ac.uk

\section{ABSTRACT}

Objectives To examine what activities constitute the work of Foundation doctors and understand the factors that determine how that work is constructed.

Design Cross-sectional mixed methods study. Questionnaire survey of the frequency with which activities specified in curricular documents are performed. Semistructured interviews and focus groups.

Setting Postgraduate medical training in the UK. Participants Doctors in their first 2 years of postgraduate practice (Foundation Programme). Staff who work with Foundation doctors - supervisors, nurses and employers (clinical; non-clinical).

Results Survey data from 3697 Foundation doctors identified curricular activities $(41 / 103,42 \%)$ that are carried out routinely (performed at least once or twice per week by $>75 \%$ of respondents). However, another 30 activities (29\%) were carried out rarely (at least once or twice per week by $<25 \%$ respondents), largely because they are routinely part of nurses', and not doctors', work. Junior doctors indicated their work constituted three roles: 'support' of ward and team, 'independent practitioner' and 'learner'. The support function dominated work, but conflicted with stereotyped expectations of what 'being a doctor' would be. It was, however, valued by the other staff groups. The learner role was felt to be incidental to practice, but was couched in a limited definition of learning that related to new skills, rather than consolidation and practice. Activities and perceived role were shaped by the organisational context, medical hierarchies and through relationships with nurses, which could change unpredictably and cause tension. Training progression did not affect what activities were done, but supported greater autonomy in how they were carried out.

Conclusions New doctors must be fit for multiple roles. Strategies for transition should manage graduates' expectations of real-world work, and encourage teams and organisations to better accommodate graduates. These strategies may help ensure that new doctors can adapt to the variable demands of the evolving multiprofessional workforce.

\section{INTRODUCTION}

The transition to medical practice is challenging for new graduates, and despite educational reform, doctors continue to struggle with the change from being a student to a qualified professional. $^{1-3}$

\section{Strengths and limitations of this study}

This national study uses mixed methods to examine systematically what activities constitute the routine work of junior (Foundation) doctors and understand the factors that may shape that work.

- Large-scale questionnaire survey and qualitative data from multiple stakeholder groups-Foundation doctors, nurses, supervisors and employers-enhance the transferability of our findings.

- Our qualitative methods give an in-depth understanding of the question, and how views may differ between participant groups.

- Our sample is large for qualitative methods (80 participants in focus groups; 44 in interviews), and the degree of agreement and triangulation between methods and participant groups gives us confidence in the rigour of our methods and validity of our findings.

- Attentional and recall biases are a risk in analysis but we have minimised these by using stimuli based on questionnaire data to support discussion.

Theoretical frameworks describing transitions refer to the adjustments that individuals make as they assume a new role in an organisation and form interprofessional relationships in the workplace. ${ }^{45}$ This experience may be less stressful when an individual's expectations align with workplace reality. ${ }^{67}$ In medicine, there is evidence that students' experience in undergraduate programmes may be able to modify how they experience the transition to work, as suggested by differing levels of anxiety among graduates according to the time spent in an apprentice role in final year at a medical school. ${ }^{8}$ However, the context of clinical practice is changing rapidly, and an evolving workforce influences the roles and workplaces into which medical graduates move. ${ }^{9}$ Hence, curricula must also reflect these changes so that educational preparation does indeed align with the reality and needs of the modern workforce.

The competences expected of junior doctors in the UK are specified by the 
regulatory body, the General Medical Council (GMC). Curricular outcomes are set out for graduates beginning work, ${ }^{10}$ and for eligibility to gain full registration (permitting 'unsupervised practice') at the end of the first postgraduate year. ${ }^{11}$ While these documents have been informed by stakeholder consultations and empirical research around graduates' preparedness for practice, ${ }^{12} 13$ there has been an assumption that the activities defined in curricula are those which graduates will be doing in the real-world setting, and so for which they should be prepared. However, the fundamental question of what they should actually be prepared for has not been directly addressed. ${ }^{1415}$

In order to ensure graduates are safe and appropriately supported in the workforce, it is critical to understand the detail of the job that they actually do in the modern workplace, and the factors which may shape that practice. However, little research has examined systematically the activities that constitute the routine practice of new doctors, and how these may develop over time. Previous studies have considered what 'should' be done, rather than what 'is' done, ${ }^{16}$ or focused on particular aspects of work, such as memorable 'firsts' ${ }^{3}$ and challenging clinical situations. ${ }^{17}$ Other literature have focused on the amount of time spent on work activities ${ }^{18}$ and their perceived educational value. ${ }^{19}$ However, methodological differences in studies, including broad categorisation of activities using varying definitions, ${ }^{20}{ }^{21}$ mean that the detail of the specific tasks performed, and the reasons for their being performed, cannot be consistently identified or compared.

A related body of literature on Entrustable Professional Activities (EPAs) has some similarity with our area of interest, in that EPAs define the essential work of a health professional in a given context. ${ }^{22}$ However, central to the EPA concept is an entrustability decision made by a supervisor about an individual trainee's ability to perform a specific activity unsupervised. By contrast, in this study, our focus is on the routine norms and work experience of all doctors entering practice. We seek to identify those activities that are, as a rule, entrusted to newly qualified doctors as a matter of course, because of common practice, and not individual judgements. Addressing this gap in the literature can offer real-life insight to inform curricular review and ways in which learning outcomes may be delivered authentically in medical school and the workplace.

This paper also adds to the literature on transitions by addressing the more fundamental question of what are junior doctors for? A greater understanding of the role and function they fulfil in the modern workforce, and how this is perceived, may elaborate why new graduates continue to struggle in the transition to professional practice and identify common themes that are open to intervention.

This study looked at the practice of Foundation Programme doctors in the UK, who are in their first 2 years of postgraduate medical training, but the questions are relevant to new doctors entering hospital practice in other developed countries. The data were collected as part of a commissioned project for the GMC, which considered findings in relation to the relevance of policy and the alignment of activities with curricular documents. This paper focuses on understanding the experience of doctors entering practice. We, therefore, briefly reiterate quantitative data of what their work comprises, before developing a qualitative analysis to consider how that work is constructed.

Specific research questions (RQs) are as follows:

1. What activities form the routine work of Foundation doctors?

2. What is the role of the Foundation doctor in the multiprofessional team?

3. What factors may shape this work?

We considered practice in different clinical and organisational settings, and as trainees progressed through the Foundation programme. We also gained the perspectives of other members of the clinical and managerial team to understand the function of these doctors from a wider organisational perspective.

\section{METHODS \\ Design}

This was a cross-sectional mixed methods study, adopting survey methodology, which was conducted in the UK between January and May 2015. Questionnaire data considered RQ1 at a population level, while a qualitative approach addressed RQ2 and RQ3 by exploring trainees' experience of the junior doctor role and the contextual views of the wider clinical team and employers.

\section{Participants}

Participants came from the following four groups:

1. Junior doctors: Foundation doctors in their first (F1) and second (F2) postgraduate years.

2. Supervisors: senior clinicians with roles as clinical or educational supervisors of Foundation doctors.

3. Nurses: nurses of any grade who work with Foundation doctors.

4. Employers: senior clinicians and others with responsibility for the deployment and allocation of Foundation doctors.

\section{Questionnaire design and distribution}

An online questionnaire was developed and piloted. This contained 103 items describing activities mapping to the then-current curricular documents (94 from the Outcomes for Graduates, ${ }^{10} 3$ from the Foundation Programme curriculum, ${ }^{11}$ plus 6 added in discussion with the GMC). These were categorised a priori as follows: administration, clinical judgement, practical skills, communication with patients, communication with colleagues, prescribing and learning.

Foundation doctors were asked how often they performed each activity 'in the last 4 weeks': 'never: I have 
not had to do this at all in this placement', 'rarely: only once or twice in this placement', 'sometimes: once or twice a week', 'often: several times a week' and 'constantly: many times per shift'.

Free text questions invited respondents to list 'other' activities that were carried out at least once or twice a week. Demographic details and questions about the current placement were also included. Once completed, the questionnaire linked to an additional page inviting respondents to provide contact details if they would like to take part in a research interview.

A version adapted for nurses asked which staff group performed each activity: 'exclusively (with occasional exceptions)', 'mostly' or 'equally' done by Foundation doctors or by nurses. A 'not applicable' option allowed for cases where the activity was done by a more senior doctor or other health professional.

The questionnaire was delivered online using the SurveyMonkey platform (https://www.surveymonkey. com). A link for trainees was cascaded by email through Foundation Schools, which manage Foundation training regionally in the UK, and for nurses through Directors of Nursing in each of the Trusts in North East England and North Cumbria.

\section{Analysis}

For analysis, the response scale for doctors was simplified by dichotomising activities into 'Rarely' (merging 'Never' and 'Rarely' points) and 'Regularly' performed (merging 'Sometimes', 'Often' and 'Constantly', and so indicating activities performed at least once or twice a week).

The relative frequency of responses from nurses and doctors were compared using Kendall's rank correlation.

\section{Interviews}

Sampling

Interviews were carried out with 21 trainees sampled randomly from 745 who had volunteered for interview. Survey data were stored separately from contact details, and so no purposive sampling on the basis of questionnaire responses was possible.

Supervisors and clinical employers $(n=18)$ were recruited by cascade of an email invitation through Foundation School managers. Five senior non-clinical employers were recruited by direct invitation from the researchers through contacts facilitated by Foundation School Directors.

All interviews were conducted by telephone and arranged at participants' convenience.

\section{Procedure}

A semistructured interview schedule was developed from the RQs. This was used as a guide for early interviews, allowing individual interviews to be responsive to participants' experiences. Later interviews were also informed by emerging findings. The interview schedule used interim questionnaire analysis as a prompt to gauge perceptions of routine and rare activities. Interview questions are available as online supplementary material 1.

Employer interviews took place after the bulk of data analysis had been completed, meaning they could be asked to reflect on key findings from questionnaire and interview data.

\section{Focus groups}

Sampling

Seven focus groups were carried out with Foundation doctors across the UK-one each in Wales and Scotland, two in different parts of Northern Ireland, two in South East England and one in North East England. Some groups were arranged to coincide with teaching sessions to guarantee trainee availability, others were arranged specifically for the project. In all groups, participants were volunteers constituting a convenience sample. There were between 4 and 18 participants in focus groups, with 58 taking part in total. While F1s were targeted in recruitment, given our focus on doctors entering practice, three F2s attended different groups.

Two focus groups with nurses were arranged through Directors of Nursing in two Trusts in North East England. There were 13 participants in one group, and 9 in the other.

\section{Procedure}

Focus groups followed a guide based on the interview schedules, and also used interim questionnaire results as a prompt.

All interviews and focus groups were audiorecorded and professionally transcribed.

\section{Analysis}

Interview and focus group transcripts were analysed using iterative thematic analysis. ${ }^{23}$ Sample transcripts were first reviewed by three researchers (BB, GV and SJ) to identify initial codes. These were applied to another set of transcripts, allowing interpretation of codes and definitions to be refined and agreed. All transcripts were then coded, with ongoing discussion among the researchers to ensure consistency. Sorted codes were reviewed to identify descriptive and cross-cutting themes through a series of iterations. These were developed into an initial narrative drafted by $\mathrm{BB}$, which was revised and agreed by all authors.

The project was supported by a Project Advisory Group, made up of stakeholders representing trainees, nurses, educators and employers. This group met three times during the study period, and their views informed iterative revisions of the analysis and interpretation.

Foundation doctors completing the survey received a certificate of participation that could be included in their learning portfolio. Participants attending focus groups were offered refreshments. 


\section{RESULTS}

\section{Questionnaire data}

Respondents

Trainee questionnaires were completed by 3697 respondents (1819 F1s; 1878 F2s), which approximates $25 \%$ of the 2014-2015 UK Foundation Programme population (http://www.foundationprogramme.nhs.uk). This is a typical response rate for online survey distribution, and is consistent with other studies. ${ }^{24}$
There were 428 respondents to the nurse questionnaire, but only 221 of these indicated that they worked regularly with Foundation doctors and responded to activity questions. A meaningful response rate cannot be calculated as we do not know the total number of nurses who work regularly with Foundation doctors. Also, the routes of online survey distribution were left to the discretion of the individual Directors of Nursing, with consequent variability in the number of eligible nurses who may have received the link.

\begin{tabular}{|c|c|c|}
\hline & Doctors & Nurses \\
\hline \multirow[t]{3}{*}{ Sex } & 2164 female (62.3\%) & 149 female $(85.1 \%)$ \\
\hline & 1279 male $(36.8 \%)$ & 24 male $(13.7 \%)$ \\
\hline & 31 prefer not to answer $(<1 \%)$ & 2 prefer not to answer (1.1\%) \\
\hline \multirow[t]{4}{*}{ Age } & $1031,20-24$ years $(29.7 \%)$ & $3,20-24$ years $(1.7 \%)$ \\
\hline & $2315,25-34$ years $(66.7 \%)$ & $18,25-34$ years $(10.3 \%)$ \\
\hline & $111,35-44$ years $(3.2 \%)$ & $47,35-44$ years $(27.9 \%)$ \\
\hline & $16,>44$ years $(0.5 \%)$ & $106,>44$ years $(60.9 \%)$ \\
\hline \multirow[t]{3}{*}{ Place of qualification } & 3227 UK medical school (93.2\%) & 169 UK (97.1\%) \\
\hline & 102 European Economic Area (2.9\%) & 2 European Economic Area (1.1\%) \\
\hline & 135 Elsewhere in world (3.9\%) & 3 Elsewhere in world (1.7\%) \\
\hline \multirow[t]{4}{*}{ Disability } & 3348 No $(96.3 \%)$ & Not recorded \\
\hline & 8 Limited a lot $(0.2 \%)$ & \\
\hline & 69 Limited a little (2.0\%) & \\
\hline & 50 Prefer not to say $(1.4 \%)$ & \\
\hline \multirow[t]{7}{*}{ Ethnicity } & 2078 White UK (60.8\%) & Not recorded \\
\hline & 276 Other white $(8.1 \%)$ & \\
\hline & 93 Black (2.7\%) & \\
\hline & 686 Asian/Asian British (20.1\%) & \\
\hline & 93 Mixed (2.7\%) & \\
\hline & 70 Other $(2.0 \%)$ & \\
\hline & 121 Prefer not to say (3.5\%) & \\
\hline \multirow[t]{2}{*}{ Medical wards/departments* } & $1072 \mathrm{~F} 1$ & 81 \\
\hline & $934 \mathrm{~F} 2$ & \\
\hline \multirow[t]{2}{*}{ Surgical wards/departments ${ }^{*}$} & $799 \mathrm{~F} 1$ & 48 \\
\hline & $386 \mathrm{~F} 2$ & \\
\hline General practice† & $379 F 2$ & 10 (includes community) \\
\hline \multirow[t]{2}{*}{ Psychiatry } & $127 \mathrm{~F} 1$ & 17 \\
\hline & $125 \mathrm{~F} 2$ & \\
\hline \multirow[t]{2}{*}{$O \& G^{*}$} & $32 \mathrm{~F} 1$ & 8 \\
\hline & $96 \mathrm{~F} 2$ & \\
\hline \multirow[t]{2}{*}{ Paediatrics* } & $82 \mathrm{~F} 1$ & 17 \\
\hline & $120 \mathrm{~F} 2$ & \\
\hline Other & & 40 \\
\hline
\end{tabular}

${ }^{*} \mathrm{~F} 1 \mathrm{~s}$ and F2s indicated whether they had worked in each specialty as either their main placement or as an on-call. Figures represent those who had worked in a specialty group.

†No F1s worked in general practice, reflecting restrictions on their prescribing in community settings. 


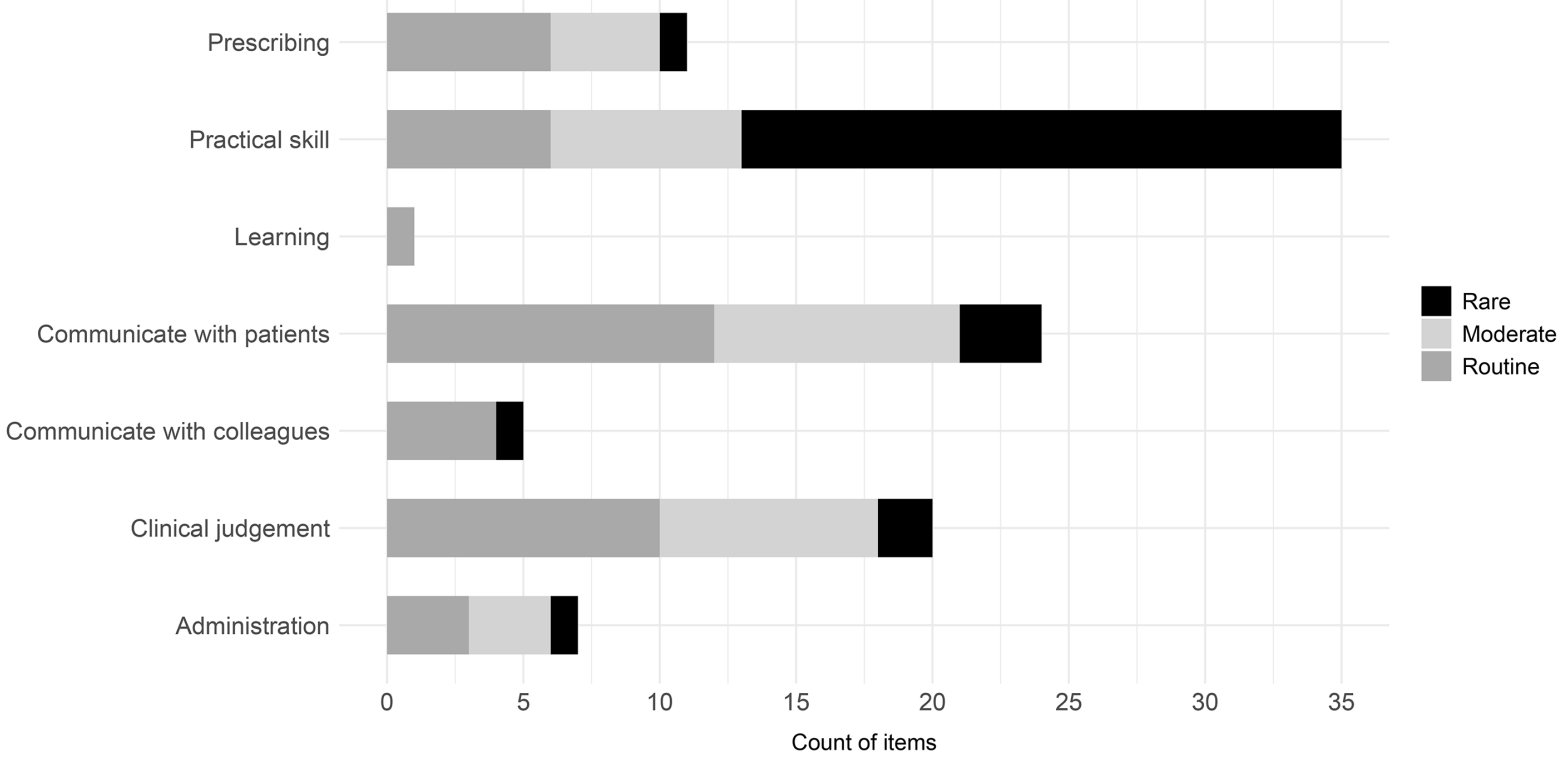

Figure 1 The frequency with which various types of activities were performed 'in the last 4 weeks' by Foundation doctors is shown. 'Routine' activities were those performed regularly by $>75 \%$ of F1s or F2s, 'rare' were those performed regularly by $<25 \%$ and 'moderate' by $\geq 25 \%$ and $\leq 75 \%$ of respondents. Routine activities constituted $41 \%$ ( $n=42)$ of questionnaire items and most often involved communication (16 of 42; 38\%). Conversely, $29 \%(n=30)$ of activities were rare. The majority of these (19 of $30 ; 73 \%)$ were related to practical skills.

The demographics of trainee and nursing respondents are shown in table 1.

\section{Routine and rare activities}

The proportion of trainees performing each activity regularly ranged between 2\% and 98\% (median 55\%; IQR 27\%-97\%). Frequencies were similar for F1s and F2s, with only a few exceptions. (Full details of responses for each item can be found in online supplementary material 2).

Activities that were 'routine' (performed regularly by $>75 \%$ of $\mathrm{F} 1$ or $\mathrm{F} 2$ respondents) and 'rare' (performed regularly by $<25 \%$ ) are shown in figure 1 , broken down by the type of activity described. Routine activities constituted $41 \%(\mathrm{n}=42)$ of questionnaire items and are listed in table 2. These were all specified in curricular documents and encompassed a range of skill types. Activities involving communication were most frequent (16 of $42 ; 38 \%)$, followed by those relating to clinical judgement (9 of 38 ).

Conversely, 29\% ( $\mathrm{n}=30)$ of activities were rare. These are presented in table 3 . The majority of these (22 of $30 ; 73 \%)$ related to practical skills. Data from the nurse questionnaire indicated that many of the rare tasks were performed by nurses. The frequency of the 'regular' and 'rare' items performed by doctors was compared with the corresponding responses from nurses. Using Kendall rank correlation, there was just modest agreement (Kendall's $\mathrm{tau}=0.26$ ) between the frequency of 'regular' responses in trainee data, and activities described as 'exclusively or mainly doctors' in the nurse data. However, there was a higher correlation between the 'rare' items and those completed 'exclusively or mainly by nurses' (tau=0.36).
This indicates that nurses were performing many of the activities that doctors were not, but that perhaps nurses do not recognise all the work done regularly by doctors.

\section{'Other' activities}

The most common 'other' practical tasks reported in free text comments were arterial gas sampling (237 responses) and nasogastric (NG) tube placement (163). Involvement in 'do not attempt resuscitation' (DNAR) discussion was the most common other communication skill (135).

\section{Qualitative data}

Analysis identified themes that related to the parameters of practice, including rare activities, and to the variability of the work experience, namely, workplace roles, organisational differences, hierarchies and leadership, division of labour and training progression. These are presented here as they related to the three RQs: first, perceptions of the content of work, to corroborate and develop the questionnaire findings; second, the underlying functions or roles that junior doctors fulfil, and finally the contextual factors that shape their experiences of work.

\section{What does a Foundation doctor do?}

Trainees agreed that the list of regular activities used as a prompt was an accurate reflection of their job ('the bread and butter' Trainee \#15, F2), and clarified why some tasks may be rare-either because there was infrequent opportunity or need (eg, 'treat a reaction following blood transfusion') or they were performed by other staff (eg, 'measure body temperature'). Of the 'other' regular activities, taking an arterial blood gas sample was felt to 
Table 2 Activities undertaken 'routinely' by F1 or F2 doctors, and nurse perceptions of those activities

\begin{tabular}{|c|c|c|c|c|}
\hline Activity & $\begin{array}{l}\text { F1 and F2: } \\
\text { frequency } \\
\text { (\%) reporting } \\
\text { 'regular' }\end{array}$ & ‘Regular' F1 & 'Regular' F2 & $\begin{array}{l}\text { Nurses: frequency } \\
\text { (\%) reporting } \\
\text { 'mainly nurses' }\end{array}$ \\
\hline $\begin{array}{l}\text { Use electronic systems to retrieve patient data } \\
\text { including results }\end{array}$ & 3457 (98.5) & $1717(99.3 \%)$ & $1740(97.8 \%)$ & $7(4)$ \\
\hline Interpret findings from history and/or examination & 3473 (97.2) & $1701(96.8 \%)$ & $1772(97.6 \%)$ & $8(4.2)$ \\
\hline Interpret the results of investigations & $3470(97.2)$ & $1717(97.7 \%)$ & $1753(96.8 \%)$ & $7(3.7)$ \\
\hline $\begin{array}{l}\text { Make clinical judgements and decisions, in } \\
\text { conjunction with colleagues }\end{array}$ & $3465(97.1)$ & $1704(97 \%)$ & $1761(97.2 \%)$ & $5(2.6)$ \\
\hline Provide a safe and legal prescription & 3502 (96.9) & 1725 (96.9\%) & 1777 (96.9\%) & $2(1)$ \\
\hline $\begin{array}{l}\text { Seek advice from other health professionals in a } \\
\text { situation of clinical uncertainty }\end{array}$ & 3404 (96.9) & $1698(98 \%)$ & $1706(95.7 \%)$ & $9(5.1)$ \\
\hline $\begin{array}{l}\text { Plan drug therapy for common indications, including } \\
\text { pain and distress }\end{array}$ & $3491(96.3)$ & $1731(97.1 \%)$ & $1760(95.6 \%)$ & $4(2)$ \\
\hline $\begin{array}{l}\text { Provide explanation, advice, reassurance and } \\
\text { support to a patient }\end{array}$ & $3390(96.1)$ & $1667(96.1 \%)$ & $1723(96.2 \%)$ & $47(25.8)$ \\
\hline Formulate a plan for treatment and management & $3359(95.7)$ & $1645(95.1 \%)$ & $1714(96.3 \%)$ & $8(4.5)$ \\
\hline Take a medical history & $3414(95.4)$ & $1646(93.4 \%)$ & $1768(97.4 \%)$ & $12(6.2)$ \\
\hline $\begin{array}{l}\text { Seek advice from other health professionals to } \\
\text { formulate a plan for treatment, management and } \\
\text { discharge }\end{array}$ & $3340(95.2)$ & $1692(97.7 \%)$ & $1648(92.7 \%)$ & $13(7.5)$ \\
\hline Formulate a plan of investigation & $3398(95.1)$ & 1650 (93.8\%) & 1748 (96.5\%) & $5(2.6)$ \\
\hline Make an initial assessment of a patient's problems & $3396(95.1)$ & $1643(93.4 \%)$ & $1753(96.7 \%)$ & $14(7.3)$ \\
\hline Formulate a differential diagnosis & $3387(94.7)$ & $1637(93 \%)$ & $1750(96.5 \%)$ & $7(3.7)$ \\
\hline $\begin{array}{l}\text { Establish a problem list and likely diagnosis or } \\
\text { diagnoses }\end{array}$ & $3379(94.7)$ & $1635(93.1 \%)$ & $1744(96.4 \%)$ & $5(2.6)$ \\
\hline Take a family and social history & 3384 (94.6) & $1626(92.2 \%)$ & $1758(97 \%)$ & $36(18.8)$ \\
\hline Perform a full physical examination & $3372(94.5)$ & $1648(93.6 \%)$ & $1724(95.2 \%)$ & $4(2.1)$ \\
\hline Access reliable information about medicines & $3404(94.1)$ & $1686(94.6 \%)$ & $1718(93.7 \%)$ & $7(3.5)$ \\
\hline $\begin{array}{l}\text { Seek professional opinion from another specialty or } \\
\text { professional }\end{array}$ & $3286(93.7)$ & $1659(95.9 \%)$ & $1627(91.6 \%)$ & $4(2.3)$ \\
\hline $\begin{array}{l}\text { Use electronic systems to enter patient information } \\
\text { (eg, discharge plan) }\end{array}$ & $3284(93.6)$ & $1656(95.8 \%)$ & $1628(91.5 \%)$ & $13(7.4)$ \\
\hline Communicate with patients of different age groups & 3287 (93.5) & $1607(92.8 \%)$ & $1680(94.2 \%)$ & $24(13.2)$ \\
\hline $\begin{array}{l}\text { Elicit a patient's questions and understanding about } \\
\text { their condition and treatment options }\end{array}$ & 3297 (93.4) & $1608(92.6 \%)$ & $1689(94.2 \%)$ & $17(9.4)$ \\
\hline $\begin{array}{l}\text { Take a drug history, covering prescribed and other } \\
\text { medication, including complementary and alternative } \\
\text { therapies }\end{array}$ & $3298(91)$ & $1580(88.5 \%)$ & $1718(93.4 \%)$ & $8(3.9)$ \\
\hline $\begin{array}{l}\text { Identify a patient's preferences for involvement in } \\
\text { decision making about their care and treatment }\end{array}$ & $3132(88.8)$ & $1497(86.1 \%)$ & $1635(91.4 \%)$ & $22(12.3)$ \\
\hline Perform venepuncture & $3253(88.3)$ & $1740(96 \%)$ & $1513(80.9 \%)$ & $76(34.9)$ \\
\hline Take a history from relatives or carers & $3155(88.3)$ & $1506(85.6 \%)$ & $1649(91 \%)$ & $27(14.1)$ \\
\hline $\begin{array}{l}\text { Help a patient to make decisions about their care, } \\
\text { including self-care, and treatment }\end{array}$ & 3086 (87.5) & $1463(84.4 \%)$ & $1623(90.6 \%)$ & $30(16.6)$ \\
\hline Participate in a multidisciplinary clinical discussion & $3104(86.9)$ & $1535(87.3 \%)$ & $1569(86.4 \%)$ & $10(5.3)$ \\
\hline $\begin{array}{l}\text { Obtain informed consent from patient for } \\
\text { investigations }\end{array}$ & $3087(86.3)$ & $1469(83.4 \%)$ & $1618(89.1 \%)$ & $9(4.8)$ \\
\hline Be involved in the prescription of controlled drugs & 3093 (85.5) & $1573(88.4 \%)$ & $1520(82.7 \%)$ & $4(2)$ \\
\hline
\end{tabular}




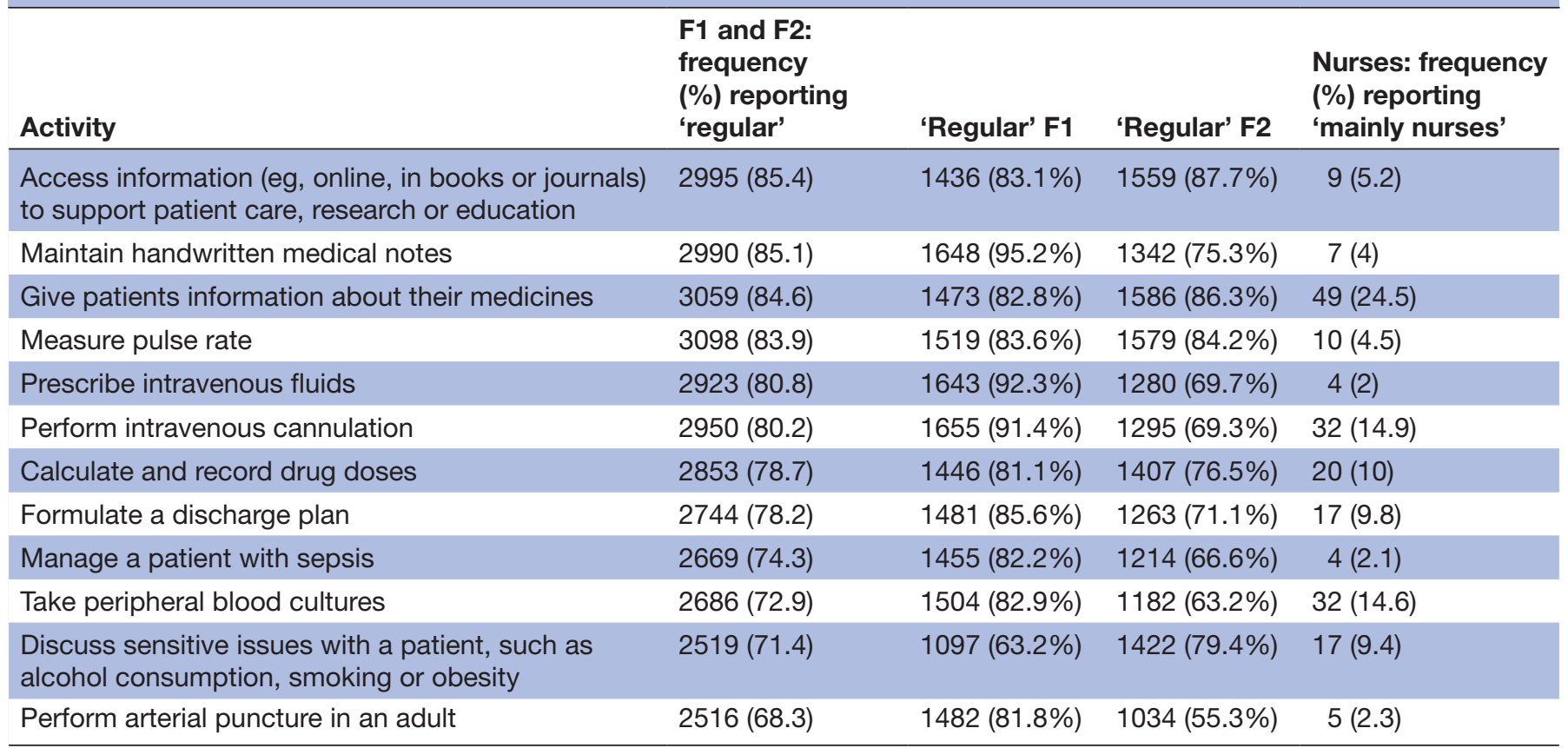

The table shows those questionnaire items indicated as being a 'regular' part of work 'in the last 4 weeks' by $>75 \%$ of F1 or F2 respondents (a 'routine' activity) and the corresponding frequency and percentage of nurse respondents who indicated that the activity was 'mainly or exclusively' done by nurses. The frequency with which 'regular' items were performed by the doctor groups was compared with the corresponding responses from nurses using Kendall rank correlation (Kendall's tau=0.26).

be a core part of their unsupervised work from day 1 of practice.

Some specialty-specific activities, for example, lumbar puncture, were recognised as complex and were performed under supervision by some trainees in those placements. However, some regular activities were also complex by virtue of having a degree of difficulty. Typically, these included NG tube placement, venous cannulation and urethral catheterisation, which Foundation doctors may be asked to do after unsuccessful attempts by nursing staff. The impact of such delegation on new doctors' experience of work is considered further in 'division of labour' below.

While end-of-life care competencies are specified by the GMC, dealing with DNAR orders was felt to be a distinct skill. One focus group elaborated this as part of a general underrepresentation at medical school of how to deal with death and dying.

Yeah, I think a lot of the time in medical school you're sort of kept away from the dying and the dead and I think you need a lot more exposure to that... I think it would make it easier for your first night shift when you're on your own and you have to go and see a person who has died. (Trainee focus group \# 6)

Other routine activities that were felt to be learnt on-the-job were managing communication between consultants and other disciplines, and supporting time management and task prioritisation through building and reviewing a 'job list'. The implication here is that there are a number of everyday tasks where lack of prior preparation has practical, and personal, consequences for trainees.

Some rare activities were still felt to be necessary in medical education and training. Trainees expressed concerns about 'deskilling' in the event of their having to use those skills in future, but there were more abstract views that doctors simply should be able to do things, implying beliefs about the nature of medicine and expected attributes of doctors.

\section{What is a Foundation doctor for?}

Trainees were aware of having varying roles or functions in the workplace. They described their work in relation to three main roles, namely, 'learner', 'support' and 'independent practitioner':

The first thing is to be trained so that I can move on to the next stage of my training... The second is to support the work of the rest of the team, in particular the senior doctors, ... then the third thing is attending to people when they become acutely unwell and being a sort of first eyes on the scene for those patients. (Trainee \#1, F1)

The dominant role was that of 'supporting' the ward team and senior doctors, with activities including admission and discharge of patients, jobs arising from ward rounds and liaison with other specialists and primary care. Trainees felt that a number of these support tasks could be more appropriately done by other staff, and implied 
Table 3 Activities undertaken 'rarely' by F1 or F2 doctors, and nurse perceptions of those activities

\begin{tabular}{|c|c|c|c|c|}
\hline Activity & $\begin{array}{l}\text { F1 and F2: } \\
\text { frequency (\%) } \\
\text { reporting 'regular' }\end{array}$ & 'Regular' F1 & 'Regular' F2 & $\begin{array}{l}\text { Nurses: frequency } \\
\text { (\%) reporting } \\
\text { 'mainly nurses' }\end{array}$ \\
\hline Treat a reaction following blood transfusion & $103(2.8)$ & $61(3.4 \%)$ & $42(2.3 \%)$ & $30(14.3)$ \\
\hline $\begin{array}{l}\text { Direct other team members to carry out } \\
\text { cardiopulmonary resuscitation }\end{array}$ & $201(5.6)$ & $75(4.2 \%)$ & $126(6.9 \%)$ & $11(5.6)$ \\
\hline $\begin{array}{l}\text { Communicate with a patient by an electronic method } \\
\text { (eg, email) }\end{array}$ & $280(7.9)$ & $115(6.6 \%)$ & $165(9.2 \%)$ & $10(5.5)$ \\
\hline Perform urethral catheterisation (female) & $292(8)$ & $165(9.2 \%)$ & $127(6.8 \%)$ & $130(61.9)$ \\
\hline Give an intramuscular injection & $318(8.7)$ & $125(6.9 \%)$ & $193(10.3 \%)$ & $201(91.8)$ \\
\hline Give a subcutaneous injection & $342(9.3)$ & $156(8.6 \%)$ & $186(9.9 \%)$ & $12(5.5)$ \\
\hline Report an adverse drug reaction & $347(9.6)$ & $155(8.7 \%)$ & $192(10.5 \%)$ & $34(16.8)$ \\
\hline $\begin{array}{l}\text { Use an airway adjunct (eg, Guedal airway or laryngeal } \\
\text { masks) }\end{array}$ & $363(9.9)$ & $144(8 \%)$ & $219(11.8 \%)$ & $19(9)$ \\
\hline Set up an infusion device for intravenous fluids & $414(11.2)$ & $221(12.2 \%)$ & $193(10.3 \%)$ & $174(79.8)$ \\
\hline Take nose, throat and skin swabs & $419(11.3)$ & $99(5.4 \%)$ & $320(17.1 \%)$ & $194(88.2)$ \\
\hline $\begin{array}{l}\text { Monitor a blood or blood product transfusion for a } \\
\text { reaction }\end{array}$ & $450(12.3)$ & $275(15.3 \%)$ & $175(9.4 \%)$ & $157(74.4)$ \\
\hline Carry out cardiopulmonary resuscitation & $454(12.6)$ & $219(12.4 \%)$ & $235(12.9 \%)$ & $15(7.7)$ \\
\hline Carry out a nutritional assessment & $464(12.6)$ & $211(11.6 \%)$ & $253(13.5 \%)$ & $163(73.8)$ \\
\hline Perform a pregnancy test & $480(13.1)$ & $99(5.5 \%)$ & $381(20.4 \%)$ & $145(66.5)$ \\
\hline Suture skin & $485(13.3)$ & $145(8.1 \%)$ & $340(18.3 \%)$ & $6(2.9)$ \\
\hline Make up a drug for intravenous administration & $520(14.1)$ & $289(16 \%)$ & $231(12.4 \%)$ & $177(80.8)$ \\
\hline Carry out wound care and basic wound dressing & $563(15.4)$ & $191(10.7 \%)$ & $372(20 \%)$ & $19(9.1)$ \\
\hline $\begin{array}{l}\text { Start a blood or blood product transfusion following } \\
\text { relevant procedures }\end{array}$ & $605(16.5)$ & $383(21.3 \%)$ & $222(11.9 \%)$ & $155(73.5)$ \\
\hline Measure blood glucose & $612(16.6)$ & $270(14.9 \%)$ & $342(18.3 \%)$ & $12(5.4)$ \\
\hline Administer an intravenous medication & $662(18)$ & $340(18.8 \%)$ & $322(17.2 \%)$ & $173(79)$ \\
\hline $\begin{array}{l}\text { Perform basic respiratory function tests (including peak } \\
\text { flow) }\end{array}$ & $689(18.7)$ & $187(10.3 \%)$ & $502(26.8 \%)$ & $140(63.9)$ \\
\hline Use a local anaesthetic (topical or injected) & $881(23.9)$ & $339(18.7 \%)$ & $542(29 \%)$ & $33(15.1)$ \\
\hline Set up an ECG monitor & $918(24.9)$ & $512(28.2 \%)$ & $406(21.7 \%)$ & $156(70.6)$ \\
\hline $\begin{array}{l}\text { Advise a patient on how to collect a midstream urine } \\
\text { specimen }\end{array}$ & $931(25.2)$ & $244(13.4 \%)$ & $687(36.7 \%)$ & $186(84.2)$ \\
\hline $\begin{array}{l}\text { Communicate with a patient by a written method (eg, } \\
\text { letter) }\end{array}$ & $937(26.6)$ & $410(23.6 \%)$ & $527(29.4 \%)$ & $9(5)$ \\
\hline Complete a death certificate & $990(27)$ & $654(36.3 \%)$ & $336(18.1 \%)$ & $1(0.5)$ \\
\hline Perform a urine multidipstick test & $1032(28)$ & $285(15.7 \%)$ & $747(39.9 \%)$ & $198(90.4)$ \\
\hline $\begin{array}{l}\text { Look for signs of abuse or neglect in children or } \\
\text { vulnerable adults }\end{array}$ & $1045(28.6)$ & $355(19.7 \%)$ & $690(37.1 \%)$ & $35(16.7)$ \\
\hline Perform urethral catheterisation (male) & $1090(29.8)$ & $662(36.7 \%)$ & $428(23 \%)$ & 78 (37.1) \\
\hline Measure body temperature & $1164(31.5)$ & $383(21.1 \%)$ & $781(41.6 \%)$ & $200(90.5)$ \\
\hline
\end{tabular}

The table shows those questionnaire items indicated as being a 'regular' part of work 'in the last 4 weeks' by $<25 \%$ of F1 or F2 respondents (a 'rare' activity) and the corresponding frequency and percentage of nurse respondents who indicated that the activity was 'mainly or exclusively' done by nurses. The frequency with which 'rare' items were performed by the doctor groups was compared with the corresponding responses from nurses using Kendall rank correlation (tau=0.36).

that some (venepuncture, in particular) may be seen as being too menial for the medical role ('I felt just like a cannula monkey'. Trainee \#10, F1). Activities involving paperwork were often identified as 'secretarial', with a common feeling of disappointment that this was 'not what they signed up for'. Such views illustrated a fundamental 
stereotyped expectation among junior doctors about what they were there to do in terms of their role and function. Conversely, nursing staff and employers (clinical and non-clinical) consistently acknowledged the importance of the support role for the effective functioning of the wider organisation. From their perspective, this was not peripheral to patient care, but, rather, central to it.

They are seen as the, to a degree, the work horses of the organisation and we would be in serious trouble without them. (Non-clinical employer \#1)

By contrast, delivering hands-on patient care, and being an independent practitioner was felt to be a more rewarding role to trainees. While they are formally, and for F1s legally, under supervision, occasions when they could apply directly their medical knowledge, decision making and responsibility in routine or emergency circumstances seemed to align best with their perceptions of a doctor as an autonomous professional, and utilised undergraduate training.

Finally, although being a learner was a central role of F1s, much of their routine work was not recognised as being of great educational value. Activities regarded as 'service provision' were an obstacle to 'learning', suggesting learning was viewed as an explicit extension of knowledge and skills, rather than implicit development of expertise through practice. The pragmatics of learning in an organisational context were further reflected by an employer, 'you cannot be just a purely training post. If that was the case, don't pay the doctors'. (Clinical employer \#1).

\section{What shapes the work of Foundation doctors? Organisational context}

Trainees generally did not feel that the type of hospital (eg, district general hospital or specialist centre) or its size shaped their work. Some suggested that smaller hospitals offered opportunities to work with greater independence. However, this could be a default arising from workforce pressures and understaffing rather than constructive provision of opportunities.

Work varied between specialties, not just because of clinical differences, but also due to the organisation of work. For example, surgical jobs often offered greater autonomy than medical jobs because more senior grades were likely to be in theatre. Similarly, F2 trainees commented on an increased level of autonomy and greater use of clinical judgement skills in general practice placements.

Work varied between daytime and out of hours working (evenings, overnight and at weekends). Out of hours work was described as mainly involving direct patient care, both on wards and in emergency admission units. Trainees and supervisors recognised valuable learning in these shifts through being exposed to new activities and responsibilities. However, this shift towards independent practitioner, with greater autonomy, was often in clinical areas with limited senior medical presence. Nurses also highlighted the common situation of small numbers of trainees covering multiple areas in the hospital and were aware of potential stress relating to many and differing demands on their skills.

Often they are the only junior doctor that is on the ward on a night or a weekend and I do think that must be quite stressful and daunting for them. (Nurse focus group 2)

\section{Hierarchy and leadership}

The specific context of clinical teams also shaped work. The most important influence in the hospital setting was the medical hierarchy, with the consensus being that trainees were at the bottom. There were, however, marked differences in the leadership approaches of individual consultants which could affect the trainee's perceived role in the team.

So the rest of the ward rounds it was more being almost like a secretary I guess, so following around the consultant, getting the notes out, scribbling in the notes. [But] it was almost like on the first [placement] we were almost leading the ward round... that was quite unique. (Trainee \#7, F2)

There was also an interaction with the nursing staff, where F1s were at the bottom of an interprofessional hierarchy, at least at the outset.

Often the buck kind of stops with you, in that the information gets filtered down the hierarchy of medicine from the consultant to the registrar to the SHO to you... And equally on the other side things come down the rungs of nurses and then it's the nurses and the F1s [who] kind of discuss things and patient care and try and formulate plans and things. (Trainee \#8, F1)

However, through this interaction, the trainee acts as a 'buffer', or interface, between medical and nursing staff, mediating between more senior doctors and nurses. This may be a function of their place at the bottom of the medical hierarchy minimising power differences between medicine and nursing. As such, this role constitutes an essential element of effective team functioning.

\section{Division of labour}

As noted in the questionnaire results, some activities were routinely completed by nurses, rather than trainees. However, many participants referred to a 'blurred line', when it was not clear which activities 'belonged' to which professional group. This blurring was accentuated when working with nurses in advanced practice roles.

Moreover, the 'line' could move unpredictably. This might reflect differing policies between Trusts and individual wards around the extended role activities that nurses could perform, but even within an area, nurse-led activities could change depending on how the senior nurse judged staff capacity and patient needs. 
So if your staff levels are low and [you're] juggling several other things then you will say-actually let's prioritise, these are the things as a nurse I have to do because nobody else is going to do it. Therefore these other things that I know I potentially could do but actually a doctor can as well. (Nurse focus group 1)

Responsibility falling to the Foundation trainee as the 'default' for certain procedures-notably cannulation, male catheterisation and NG tube insertion- often in situations of difficulty meant that tasks, which were often carried out routinely by nurses, were sometimes felt to be inappropriately passed to less experienced doctors.

Having done one male catheter in my life all the nurses ask me to do the really difficult prostate ones which I don't know how we're meant to. What we literally do differently to a nurse is absolutely nothing, but for some reason we get asked to do them. (Trainee focus group 3a)

This shifting responsibility could cause uncertainty in what was expected of the junior doctor, and tension between medical and nursing staff at times.

\section{Training progression}

While questionnaire data found little difference in activities carried out by F1s and F2s, qualitative data identified nuanced progression in activities and roles over time. While there is a statutory, regulatory change in progression, with F1s being provisionally registered with the GMC and gaining full registration before F2, this was not mentioned by doctors. The activities may be the same, but the way in which they carried these out was different, with development of prioritisation and time management skills and a greater sense of control and autonomy.

When I first started I was like, I don't think I'm ever going to be like [the F2s] in a year's time. That was my sort of joke, but certainly you become more organised and you become certainly more efficient at everything and so, and I think prioritising things becomes easier. (Trainee \#16, F1)

Nurses also noted the development of individual doctors, and the importance of early support in the interprofessional team.

They very much appreciated our help when they were newbies in August... By the time you meet the same doctor at the end of F2 and they're a different person because they've grown into their own skin and are much more comfortable in being a doctor. (Nurse focus group 2)

Perception of learning also changed with time, and some F2s were able to identify value in retrospect from support activities that had, at the time, seemed unrewarding. This suggests that their view of learning had changed to see learning as development of expertise, rather than exposure to new tasks or activities.

\section{DISCUSSION}

\section{Principal findings}

We have identified the activities that make up the routine work of junior doctors in the UK and, for the most part, these are specified in regulatory documents. Also, there were notably a number of specified activities that were rare in practice, largely because they were routinely part of nurses', and not doctors', work.

Trainees reported three roles in practice: support of ward and team, independent practitioner and learner. The support role was accepted, but often not embraced by trainees, whereas the sense of being a practitioner with direct responsibility for clinical care (although under supervision) better aligned with their expectation of what medicine, and being a doctor, was meant to be. Both of these practice-oriented roles dominated that of learner, which perhaps reflected a narrow view of what 'learning' constitutes in a practice setting.

The prevailing role was fluid and determined by a number of contextual factors. Here, the ward culture, established by senior medical and nursing staff, was critical. Some consultants were highly directive (implicitly associating the F1 more closely with the support role), while others prioritised the learner role and actively provided new opportunities. Senior nurses also shaped the F1 role in establishing what activities were a 'nurse's job' or a 'doctor's job', though the demarcation was often simply implicit in working practices. There were times when trainees could be expected by nurses to perform challenging tasks, even though they may have had less experience of them, because they were defined as doctor's jobs. This assertion of an interprofessional hierarchy by nurses has been noted in the literature, ${ }^{25}$ and suggests the 'negotiated order' of interprofessional work ${ }^{26} 27$ is not always negotiable. In this circumstance, tension could arise when trainees experienced differing doctor-nurse working relationships across wards, sometimes in a single shift, with unanticipated expectations of practice.

\section{Strengths and weaknesses}

This large-scale national study has provided unique insight into the work of Foundation doctors. It is novel in also describing the functions, or roles, that junior doctors are expected to fulfil in the workplace, drawing on the perspectives of trainees in different specialties and geographic areas, as well as multiple stakeholder groups. In reframing the work of a junior doctor in relation to organisational needs, the findings indicate that educational preparation should consider not just what skills a new graduate requires, but also why they are required, so that their capabilities and expectations better align to the requirements of the modern clinical workforce.

Our questionnaire was completed by around $25 \%$ of Foundation doctors in the UK, and by just over 220 eligible nurses in the North East of England. Accordingly, we cannot guarantee a representative response. Nonetheless, the sample size was sufficient for our analysis, and the trainee sample demographics reflected those of the 
GMC's National Trainee Survey (personal communication, GMC), which is a close approximation of the target population.

Our qualitative samples were opportunistic, being based largely on volunteers from questionnaire respondents. However, our total sample of Foundation doctors (79 across focus groups and interviews) is large for qualitative methods. In our approach we have tried to address the risk of attentional and recall biases by introducing stimuli based on questionnaire data. Further, the degree of agreement and triangulation between methods and participant groups gives us confidence in the rigour of our methods and validity of our findings. Lastly, the review of findings provided by representatives of relevant stakeholder groups in the Project Advisory Group also strengthens our claims.

\section{Consideration of other studies}

An understanding of how new doctors experience transition is fundamental to medical education so that strategies may help to minimise the gap between undergraduate studies and work. Previous studies have often interrogated transitions through perceptions of "preparedness', ${ }^{28-31}$ but this approach is problematic conceptually, and is subject to differing definitions and perceived construct. ${ }^{141532}$ More especially, preparedness does not necessarily relate to the actual work done by new doctors. Similarly, while recent work on EPAs is concerned with critical aspects of professional work, the concept is underpinned by an entrustment decision that focuses on an individual's safety and competence, and level of supervision needed in a given environment. ${ }^{22}$ By contrast, our work is concerned about the detail of workplace norms and practice expectations, though may link to the EPA literature in that we report activities that implicitly need to be entrustable at graduation ('core basic EPAs' developed for one undergraduate curriculum ${ }^{334}$ ) as the doctor may be expected to perform these without immediate supervision on day 1 of practice.

This study adds to the evidence base around transition by describing what activities constitute routine practice, and considering how junior doctors 'fit in' into the work environment. An understanding of what graduates are 'for', and the challenges associated with this, can help inform educational strategies that are authentic to practice.

We noted that Foundation doctors' perception of what constituted medical work, and what 'they signed up for', conflicted with the more mundane reality of practice and perhaps reflected underlying stereotypes. This had consequences for trainees' satisfaction with their work, by disrupting their expectation of what a doctor is after graduation. Such a disruption may be a necessary element of their socialisation into the professional role, which has been shown to involve adaptation to unexpected aspects of practice. ${ }^{35}$ However, noting the evidence from the transition psychology literature, the experience may be less stressful if undergraduate preparation better reflects what 'being a doctor' actually means in the real-world organisational context. ${ }^{7}$

\section{Meaning of the study: explanations and implications}

Our findings suggest that new doctors' expectations of work are partial, and support interventions that prepare students for the unpredictable adjustments needed in different settings. The plurality of the junior doctor role, which emphasises the critical importance of support activities in systems of healthcare and the valuable learning opportunities afforded by workplace experiences, ${ }^{36}$ are aspects that could also be better exploited in medical school and induction programmes. These may encompass management of specific expectations of what the job involves, but also a broader element addressing perceptions of what medicine is, and how medical roles and functions interface with the developing competencies and responsibilities of other professionals in the modern workforce.

The relationship with nurses was central to how the Foundation doctors experienced their role. Our findings suggest that new doctors may struggle to adapt to variability in the nurse workforce and resultant expectations of practice. Collaborative interprofessional working is central to patient safety and quality of care, ${ }^{37}$ and both nursing and medical curricula should emphasise the importance of a mutual understanding of each other's roles and capabilities, and how, and why, these may vary between different contexts. It is important that clearly defined outcomes relating to gaining experience of interprofessional working are established and that differences in undergraduate learning contexts do not dilute learning about the work of other professions, or integration into a multiprofessional team from an early stage.

\section{Unanswered questions and further work}

Our survey data provide important detail on the content of junior doctors' work in the UK, but also raise questions for employers around workload, workforce planning and relevant quality assurance. Our finding that there is a set of activities that are rarely performed by Foundation doctors also challenges educators to consider how these learning outcomes may best be addressed. Outstanding questions centre on the interactions between doctors and nurses, and the factors that determine effective working relationships and deployment of skill sets. Nurses are integral to the support and training of Foundation doctors and it is essential that this culture is promoted in the workplace.

This work notes tension that arises when expectations of work are at odds with reality. The implication of this mismatch for individuals' self-concept, including professional identity and well-being, is worthy of further study. Further, our work predated introduction of a new contract for junior doctors working in England's National Health Service and the effect on the activities and experience of doctors entering practice from differing systems and conditions of work are important issues to consider. 
Our findings also provide evidence to support education interventions-through medical school and into the Foundation Programme-which are based on approaches that equip students with the skills to adapt to transition challenges, and support the clinical team and organisation to better accommodate graduates in the workplace. These strategies will need investigation and evaluation.

Acknowledgements We are grateful to education leads and administration teams across the UK who facilitated set up of focus groups in local sites. We are also grateful for the time and expertise of members of the project advisory group and for the valuable contributions of all study participants.

Contributors The study was conceived and designed by GV, BB and JS. GV, $\mathrm{BB}$ and SJ collected and analysed the data and all authors contributed to data interpretation. GV wrote the manuscript, and all authors contributed to subsequent revisions and approved the final manuscript.

Funding This work was commissioned and funded by the General Medical Council (grant number GMC236). The GMC was kept informed of progress with the collection, interpretation and analysis of the data, but the research team remained independent of the funders. The GMC approved the final report and gave permission for submission of the manuscript for publication.

Competing interests None declared.

Patient consent for publication Not required.

Ethics approval NHS ethical review was not required, but full ethical approval was given by Newcastle University Faculty of Medical Sciences Ethics Committee (reference 00845/2014).

Provenance and peer review Not commissioned; externally peer reviewed.

Data sharing statement Full data from the study are publicly available on the GMC website (for full report, see https://www.gmc-uk.org/-/media/documents/ activities-of-fp-doctors-full-report-final-210915_pdf-62792484.pdf and for appendices, see https://www.gmc-uk.org/-/media/documents/Activities_of_FP_ doctors_Appendices_FINAL_210915.pdf_62792850.pdf).

Open access This is an open access article distributed in accordance with the Creative Commons Attribution Non Commercial (CC BY-NC 4.0) license, which permits others to distribute, remix, adapt, build upon this work non-commercially, and license their derivative works on different terms, provided the original work is properly cited, appropriate credit is given, any changes made indicated, and the use is non-commercial. See: http://creativecommons.org/licenses/by-nc/4.0/.

\section{REFERENCES}

1. Monrouxe L, Bullock A, Cole J, et al. How prepared are UK medical graduates for practice: Final report from a programme of research commissioned by the General Medical Council. Cardiff: General Medical Council, 2014

2. Brennan N, Corrigan O, Allard J, et al. The transition from medical student to junior doctor: today's experiences of Tomorrow's Doctors. Med Educ 2010;44:449-58.

3. Lefroy J, Yardley S, Kinston R, et al. Qualitative research using realist evaluation to explain preparedness for doctors' memorable 'firsts'. Med Educ 2017;51:1037-48.

4. Nicholson N. A theory of work role transitions. Adm Sci Q 1984:29:172-91.

5. Duchscher JE. Transition shock: the initial stage of role adaptation for newly graduated registered nurses. J Adv Nurs 2009;65:1103-13.

6. Adkins CL. Previous work experience and organizational socialization: a longitudinal examination. Acad Manage $J$ 1995;38:839-62.

7. Brett JM. Job transitions and personal and role development. In: Rowland KM, Ferris GR, eds. Research in personnel and human resources management 2. Greenwich, CT: JAI Press, 1984:155-85.

8. Van Hamel C, Jenner LE. Prepared for practice? a national survey of UK foundation doctors and their supervisors. Med Teach 2015;37:181-8.
9. Addicott R, Maguire D, Honeyman M, et al. Workforce planning in the NHS. London: The King's Fund, 2015.

10. GMC. Outcomes for graduates: General Medical Council, 2015.

11. UKFPO. The foundation programme curriculum: United Kingdom Foundation Programme Office, 2012.

12. Illing J, Morrow G, Kergon C, et al. How prepared are medical graduates to begin practice? a comparison of three diverse UK medical schools: Final report to GMC 2008.

13. Monrouxe L, Bullock AD, Rees C, et al. Foundation doctors, transitions and emotions: Final report to the GMC. 2015.

14. Monrouxe LV, Bullock A, Gormley G, et al. New graduate doctors' preparedness for practice: a multistakeholder, multicentre narrative study. BMJ Open 2018;8:e023146.

15. Burford B, Vance G. When I say ... preparedness. Med Educ 2014:48:849-50.

16. Stewart J, O'Halloran C, Harrigan P, et al. Identifying appropriate tasks for the preregistration year: modified Delphi technique. BMJ 1999;319:224-9.

17. Lundin RM, Bashir K, Bullock A, et al. "I'd been like freaking out the whole night": exploring emotion regulation based on junior doctors' narratives. Adv Health Sci Educ Theory Pract 2018;23:7-28.

18. Tipping MD, Forth VE, Magill DB, et al. Systematic review of time studies evaluating physicians in the hospital setting. $J$ Hosp Med 2010;5:353-9.

19. Boex JR, Leahy PJ. Understanding residents' work: moving beyond counting hours to assessing educational value. Acad Med 2003;78:939-44.

20. Block L, Habicht R, Wu AW, et al. In the wake of the 2003 and 2011 duty hours regulations, how do internal medicine interns spend their time? J Gen Intern Med 2013;28:1042-7.

21. Westbrook JI, Ampt A, Kearney L, et al. All in a day's work: an observational study to quantify how and with whom doctors on hospital wards spend their time. Med J Aust 2008;188:506.

22. Ten Cate O, Chen HC, Hoff RG, et al. Curriculum development for the workplace using entrustable professional activities (EPAs): AMEE guide no. 99. Med Teach 2015;37:983-1002.

23. Braun V, Clarke V, Terry G. Thematic analysis. Qual Res Clin Health Psychol 2014;24:95-114.

24. Nulty DD. The adequacy of response rates to online and paper surveys: what can be done? Assess Eval High Educ 2008;33:301-14.

25. Burford B, Morrow G, Morrison J, et al. Newly qualified doctors' perceptions of informal learning from nurses: implications for interprofessional education and practice. $J$ Interprof Care 2013;27:394-400.

26. Svensson R. The interplay between doctors and nurses $-a$ negotiated order perspective. Sociol Health IIIn 1996;18:379-98.

27. Allen D. The nursing-medical boundary: a negotiated order? Sociol Health IIIn 1997;19:498-520.

28 Kellett J, Papageorgiou A, Cavenagh P, et al. The preparedness of newly qualified doctors-Views of Foundation doctors and supervisors. Med Teach 2015;37:949-54.

29 Burford B, Whittle V, Vance GH. The relationship between medical student learning opportunities and preparedness for practice: a questionnaire study. BMC Med Educ 2014;14:223.

30 Tallentire VR, Smith SE, Skinner J, et al. The preparedness of UK graduates in acute care: a systematic literature review. Postgrad Med J 2012;88:365-71.

31 Alexander C, Cameron A, Millar J, et al. Can new doctors be prepared for practice? A review. Clin Teach 2014;11:188-92.

32 Kilminster S, Zukas M, Quinton N, et al. Preparedness is not enough: understanding transitions as critically intensive learning periods. Med Educ 2011;45:1006-15.

33 Chen HC, van den Broek WE, ten Cate O. The case for use of entrustable professional activities in undergraduate medical education. Acad Med 2015;90:431-6.

34 Ten Cate O, Graafmans L, Posthumus I, et al. The EPA-based Utrech undergraduate clinical curriculum: Development and implementation. Med Teach 2018;40:506-13.

35 Pratt MG, Rockmann KW, Kaufmann JB. Constructing professional identity: the role of work and identity learning cycles in the customization of identity among medical residents. Acad Manage $J$ 2006;49:235-62.

36. Billett S. Workplace participatory practices: conceptualising workplaces as learning environments. Journal of Workplace Learning 2004:16:312-24.

37. Kenaszchuk C, Wilkins K, Reeves S, et al. Nurse-physician relations and quality of nursing care: findings from a national survey of nurses. CJNR 2010;42:120-36. 